\title{
A New Business Mode for FTs Chain in an E-Commerce Environment
}

\author{
Xihui Wang, Yonggang Wu, and Liang Liang \\ The School of Management, University of Science and Technology of China, Hefei 230026, China \\ Correspondence should be addressed to Yonggang Wu; wyg2012@mail.ustc.edu.cn
}

Received 26 March 2014; Revised 15 May 2014; Accepted 19 June 2014; Published 9 July 2014

Academic Editor: Xiaohang Yue

Copyright (C) 2014 Xihui Wang et al. This is an open access article distributed under the Creative Commons Attribution License, which permits unrestricted use, distribution, and reproduction in any medium, provided the original work is properly cited.

With the rise in the online demand for fashion and textiles (FTs) along with the development of e-commerce, a business mode called drop-shipping mode has emerged. Despite the fact that the drop-shipping mode has many merits, this method has less earning power compared with the traditional business mode. This study proposes a mix business mode for FTs chains in an ecommerce environment. Traditional and drop-shipping modes are special cases of the mix mode. In addition, a generalized model is built to analyze the profitability of FTs chains. Our study shows that, in most cases, the mix mode improves overall profit of FTs chain. Moreover, we consider the seasonality and the short life cycle of fashion items in analyzing the relationship between the e-retailer's optimal inventory level and demand distribution parameters. The numerical example shows that, by changing their inventory level, e-retailers can address the demand fluctuation using the mix mode. The proposed mix mode employs both business modes to enhance the profitability of a FTs chain. As such, the mix mode is an effective method to address demand fluctuation for FTs in an e-commerce environment.

\section{Introduction}

Fashion and textiles (FTs), which are an essential aspect of our social life, significantly contribute to economic growth and employment. The rapid increase in development of ecommerce has led to the increase in the online demand for FTs. Most customers find purchasing in retail stores to be time consuming because of the need to deliberate on sizes, styles, colors, brands, and so on $[1,2]$. In addition, the FTs business is seasonal and has a short life cycle. In-store purchasing may limit sales. In this regard, e-commerce benefits FTs businesses through convenience, low costs, and time. These features extend the potential online sales of FTs and provide new opportunities for the FTs business. In recent years, the fashion e-trade in China has grown tremendously, as indicated by market survey reports [3-5].

In the traditional business mode, retailers in FTs businesses purchase goods from suppliers and then store the goods in warehouses. When a customer places an order for certain goods, the retailer delivers the goods directly to the customer and makes profit from the service. In e-commerce, a new business mode has emerged called the drop-shipping mode $[6,7]$. In this mode, e-retailers simply forward an order to suppliers (or manufacturers), who then deliver the order directly to customers. With this mode, e-retailers can avoid inventory risks, while benefitting from many advantages such as having low operating cost, low inventory risk, and high flexibility. However, e-retailers gain less profit from the dropshipping mode compared with the traditional mode, as they are not in full control of the goods in the former. By contrast, the traditional mode allows e-retailers to gain more profits from each order but requires more operating capital and risk.

The demand for FTs is uncertain, particularly when accidental factors exist, such as festivals and football games. E-commerce amplifies the demand fluctuation, thus making demand forecasting difficult. Several methods can be adopted to forecast the demand for short cycle goods or seasonal products, such as ARIMA, collaborative forecasting [8], the Bass model $[9,10]$, and BP neural network predictive method. However, these methods are not suitable for the situations discussed in this study.

Given the characteristics of e-commerce, neither dropshipping mode nor traditional mode meets the market demand under great uncertainty and drastic fluctuation 
solely. Therefore, combining these two modes is necessary to solve this problem. In forecasting FTs demand, we add qualitative information to the demand distribution model for cases with drastic demand fluctuation. Thus, a general eretailer and supplier profit model is built. The rest of the study is organized as follows.

In Section 2, we review the literature on FTs in ecommerce, the predictive methods for short life cycle products, the drop-shipping mode, and the traditional mode. In Section 3, we discuss the mix mode, analyze the different modes, and determine the profit conditions under Pareto improvement. In Section 4, the demand process of FTs is described, and a loss function is built to optimize adjustment parameter $\theta$. In Section 5, a numerical example under drastic demand fluctuation is examined. Finally, we list the conclusions of the study in Section 6.

\section{Literature Review}

With the development of e-commerce, more customers opt to purchase FTs through the Internet. Hence, an increasing number of scholars focus on the management problem of FTs in e-commerce [11, 12]. E-commerce has two main business modes: (1) the traditional mode, in which the retailer delivers goods directly to the customer from his own warehouse, and (2) the drop-shipping mode, in which the retailer simply forwards the customers' order to the supplier (or manufacturer), who then fulfills the order. In recent years, online retailers have used the drop-shipping mode as an order fulfillment strategy [13]. Netessine et al. [14] studied the conditions in which the drop-shipping mode was more effective than the traditional mode. Bailey et al. [15] proposed that retailers should use the traditional mode for products that are popular. As [16] reported, the drop-shipping mode results in cost savings but reduces profitability, whereas the traditional mode provides a higher profit from each unit [16]. However, e-retailers may encounter high inventory risks when demand uncertainty is high. Moutaz [17] and Khouja et al. [18] classified customer demand into two levels and adopted different modes. In the present study on FTs business in e-commerce, we combine the traditional and drop-shipping modes to integrate the advantages of both modes.

The demand for FTs has the following features: seasonality, high volatility, low predictability, and short life cycle [19]. The types of demand prediction methods used for FTs include the collaborating forecasting model and the Bass model. Several studies on the collaborating model can be found. Aviv [8] studied the interaction between inventory and forecasting in a two-stage supply chain of a single product with stochastic demand. Donohue [20] proposed an efficient supply contract for fashion goods with forecast updating and identified the conditions ensuring a Pareto optimal solution with respect to two traditional production settings. Xie et al. [21] proposed a novel ensemble learning approach based on logistic regression and an artificial intelligence tool. They suggested that the proposed approach, which was a modified collaborating forecasting model, could achieve higher forecasting performance than individual models. The Bass model, which was proposed in 1969 by Bass [9], basically assumes that customer purchase behavior towards new products has an imitative ability: when one customer buys a new product, purchasing behavior diffuses and affects the behavior of other customers [17]. Moreover, ARIMA and BP neural network predictive methods are fit for predicting the demand for short life cycle products [22-24]. Nevertheless, these methods do not take accidental factors into consideration. Thus, in the present study, we describe the demand process of FTs and include demand peak information to the model. The approach proposed in this study is a combination of qualitative and quantitative methods.

With the aim to analyze the characteristics of FTs in ecommerce, we propose a mix mode where e-retailers simultaneously adopt traditional and drop-shipping modes to fulfill online orders. Further, we add qualitative information to our loss model to obtain the e-retailer optimal inventory level.

\section{Mix Strategy Model}

FTs chains are timeliness and seasonal; some types of fashion may even have short life cycles. We address these problems using a single-period model framework. Typically, if fashion products are not sold by the end of a period (season), a discount strategy is employed to sell them or these products are disposed. Given that these characteristics fit the classical newsvendor model, the classical single-period problem (SPP) model is adapted for building our model.

In this paper, we propose a mix business mode described as follows: if the demand can be satisfied by the e-retailer's own inventory, then the e-retailer will ship the good to the customer directly and assume responsibility for courier delivery. Otherwise, the e-retailer forwards the excess orders to the supplier to satisfy the additional demand.

3.1. Some Notations and Assumptions. We define the following notations for simplicity:

$x$ quantity demanded in one period for a particular fashion type; a random variable with known probability density function;

$f(x)$ probability density function of $x$;

$F(x)$ cumulative distribution function of $x$;

$\mu=E[x]$ expected value of demand $x$;

$p$ per unit selling price from the e-retailer of a particular fashion type;

$w$ per unit order price from the supplier;

$c$ per unit cost of a particular fashion type for the supplier;

$Q$ production quantity of the supplier; a decision variable;

$q$ order quantity in one period; a decision variable;

$\theta$ proportion of quantity used for in-house inventory to order quantity $q$; a parameter variable; hence, $\theta \cdot q$ represents the e-retailer inventory quantity; 
$t_{\text {Re }}$ per unit transportation cost of the e-retailer under the traditional mode;

$t_{\text {Su }}$ per unit transportation cost of the supplier under the drop-shipping mode; typically, the transportation cost between e-retailers and suppliers is different, and this unit difference is noted as $\delta=t_{\mathrm{Re}}-t_{\mathrm{Su}}$;

$\eta$ risk compensation from the e-retailer to the supplier for a fashion type, including per unit transportation $\operatorname{cost} t_{\mathrm{Su}} ; \eta_{0}=\eta-t_{\mathrm{Su}}$ represents net risk compensation; given that the supplier is confronted with inventory and transportation risks under the drop-shipping mode, the e-retailer pays $w+\eta$ per unit for one fashion type to the supplier;

$\tau_{\text {Re }}$ per unit shortage penalty cost of the e-retailer;

$\tau_{\text {Su }}$ per unit shortage penalty cost of the supplier;

$s_{\text {Re }}$ per unit salvage value of unsold fashion type for the e-retailer;

$s_{\text {Su }}$ per unit salvage value of unsold fashion type for the supplier;

$v$ per unit inventory cost of the retailer.

Given that $0<s_{\mathrm{Re}}, s_{\mathrm{Su}}, s_{\mathrm{Re}}, s_{\mathrm{Su}_{\mathrm{u}}}<c$ and $c<w$, we assume that $0<s_{\mathrm{Re}}, s_{\mathrm{Su}}<c<w<w+\eta_{0}<p<p+\delta$, which ensures that a sale is profitable in both modes. The relationship $w+$ $\eta_{0}<p$ indicates that an e-retailer can gain profit in the dropshipping mode, even though he pays risk compensation to the supplier. made.

To formulate the model, the following assumptions are

(a) The selling price $p$ is the same for both traditional and drop-shipping modes.

(b) The demand for a particular fashion type $x$ in one period is a random variable with a known distribution $F(x)$.

(c) Owing to the scale effect and fierce competition in the express delivery industry, the transportation cost of the e-retailer is higher than the transportation cost of the supplier; that is, $0<t_{\mathrm{Su}}<t_{\mathrm{Re}}$ and $\delta>0$.

Assumption (a) ensures that customers are unaware of the mode used to satisfy the fashion demand. Under the mix mode, e-retailers satisfy the excess fashion demand, particularly when a sales promotion is employed or an occasion arises (e.g., a basketball game).

3.2. E-Retailer and Supplier Profit Model under the Mix Mode. We discuss a simple FTs supply chain that includes a fashion e-commerce retailer and a fashion supplier. We assume that this supply chain is engaged in a single type of fashion or textile. Figure 1 shows the change in the e-retailer and supplier's inventory levels as the demand grows under the mix mode.

In Figure 1, the e-retailer orders $q$ units from the supplier at the beginning of a demand season. However, instead of reserving all ordered goods in his own warehouse, the eretailer only stores $\theta \cdot q(0 \leq \theta \leq 1)$ units. For the remaining

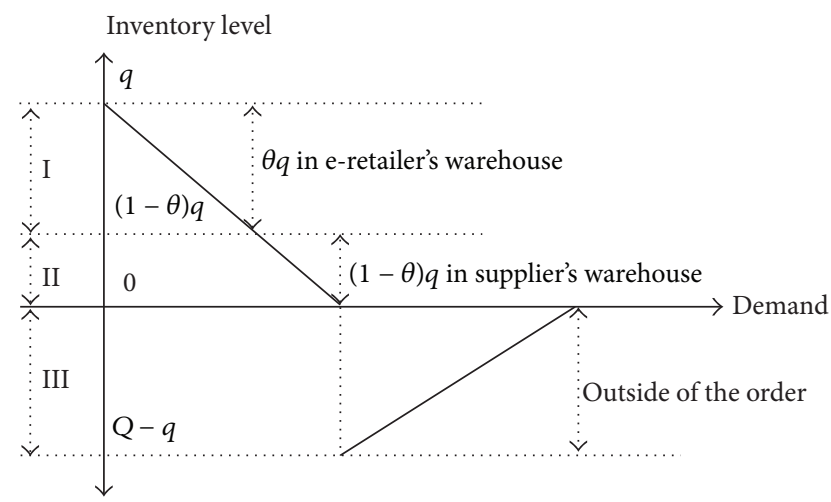

Figure 1: Mix mode in one demand season.

part $(1-\theta) q$, the e-retailer asks the supplier to store the goods for him and pay $s_{\text {Su }}$ per unit to the supplier as a deposit. When the demand is between 0 and $\theta q$ (i.e., region I in Figure 1), some fashion items are left unsold in the eretailer warehouse, that is, the excess capacity $\theta q-x$. The salvage value $s_{\mathrm{Re}}$ of unsold goods is less than selling price $p$. When the demand is between $\theta q$ and $q$ (i.e., region II in Figure 1), the e-retailer satisfies demand with the goods in his warehouse $\theta \cdot q$ and asks the supplier to satisfy the remaining demand $x-\theta q$ with the goods in the supplier's warehouse. In this situation, the supplier takes a risk; hence, the e-retailer pays $\eta_{0}$ compensation per unit to the supplier; the e-retailer achieves net profit $p+\delta-\left(w-s_{\mathrm{Su}}+\eta_{0}\right)$ per unit. When the demand is higher than order $q$ (i.e., region III in Figure 1), the e-retailer tries to satisfy demand with the goods he initially ordered. The unsatisfied demand $x-q$ is then sent to the supplier, and the e-retailer pays $w+\eta_{0}$ per unit. In this case, the e-retailer net profit is $p+\delta-\left(w+\eta_{0}\right)$ per unit. Furthermore, when demand is too high that even the supplier storage cannot satisfy it, the e-retailer has to cover a shortage cost [i.e., $\left.\tau_{\mathrm{Re}} \cdot E(x-Q)^{+}\right]$. Thus, we obtain the eretailer expected profit, given by

$$
\begin{aligned}
\pi_{\mathrm{Re}}(q)= & p \cdot E \min (x, \theta q)+\left[p+\delta-\left(w-s_{\mathrm{Su}}+\eta_{0}\right)\right] \\
& \cdot E \min \left((1-\theta) q,(x-\theta q)^{+}\right) \\
& +\left[p+\delta-\left(w+\eta_{0}\right)\right] \cdot E \min \left(Q-q,(x-q)^{+}\right) \\
& +s_{\mathrm{Re}} \cdot E(\theta q-x)^{+}-(w+v) \cdot \theta q-s_{\mathrm{Su}} \cdot(1-\theta) q \\
& -\tau_{\mathrm{Re}} \cdot E(x-Q)^{+},
\end{aligned}
$$

where expression $(a)^{+}$is operator $\max (a, 0)$.

The supplier's profit is derived from the e-retailer's payment. Under the mix mode, the supplier stores $(1-\theta) q$ units of goods for the e-retailer in his warehouse and receives a deposit of $s_{\text {Su }}$ per unit; otherwise, the supplier will not store goods for the e-retailer. When the demand is between 0 and $\theta q$ (i.e., region I in Figure 1), the e-retailer satisfies demand independently, and thus the remaining goods become a surplus in the supplier warehouse by the end of the demand 
season. In this case, the leftover value belongs to the supplier. When demand is between $\theta q$ and $q$ (i.e., region II in Figure 1), the supplier receives a request by the e-retailer to drop goods to customers and receives risk compensation $\eta_{0}$ per unit. Therefore, the supplier can get $w-s_{\text {Su }}+\eta_{0}$ per unit for the drop-shipping part of this situation. When the fashion demand is between order $q$ and production $Q$, the supplier likewise receives compensation $\eta_{0}$ per unit for the dropshipping part $\min \left(Q-q,(x-q)^{+}\right)$. Similarly, when the demand is too high for the e-retailer that even the supplier's production capacity cannot satisfy it, the e-retailer will suffer from a shortage penalty of $\tau_{\text {Su }}$ per unit. Therefore, the adapted newsvendor model of the supplier's expected profit within a period is given by

$$
\begin{aligned}
\pi_{\mathrm{Su}}(Q)= & w \cdot \theta q+s_{\mathrm{Su}} \cdot(1-\theta) q+\left(w-s_{\mathrm{Su}}+\eta_{0}\right) \\
& \cdot E \min \left((1-\theta) q,(x-\theta q)^{+}\right) \\
& +\left(w+\eta_{0}\right) \cdot E \min \left(Q-q,(x-q)^{+}\right) \\
& +s_{\mathrm{Su}} \cdot E(q-\max (x, \theta q))^{+} \\
& +s_{\mathrm{Su}} \cdot E(Q-\max (x, q))^{+} \\
& -c Q-\tau_{\mathrm{Su}} \cdot E(x-Q)^{+}
\end{aligned}
$$

The e-retailer expected profit, as shown in (1), is a function of $q$, and the supplier's expected profit given in (2) is a function of $Q$. Both $\pi_{\mathrm{Re}}(q)$ and $\pi_{\mathrm{Su}}(Q)$ are affected by the adjustable parameter $\theta$, which implies that the business mode influences the profit of both parties. In the succeeding section, we discuss the optimal decision when $\theta$ has different values.

3.3. Solution. In this study, the mix mode is a risk sharing strategy; that is, the e-retailer assumes partial inventory risk to increase the profit of both parties by adjusting the value of parameter $\theta$, which represents the e-retailer storage level. A high $\theta$ value implies that the e-retailer stores more goods and takes more risks. When $0 \leq \theta \leq 1$, we can obtain the e-retailer's optimal order quantity $q_{c}^{*}$ and the fashion supplier's production quantity $Q_{c}^{*}$ from (1) and (2). The firstorder partial derivative of $\pi_{\mathrm{Re}}(q)$ on $q$ in (1) is

$$
\begin{aligned}
\frac{\partial \pi_{\mathrm{Re}}(q)}{\partial q}= & \theta\left(\eta_{0}-v-\delta\right)-s_{\mathrm{Su}} F(q) \\
& +\theta\left(s_{\mathrm{Re}}+\delta+s_{\mathrm{Su}}-w-\eta_{0}\right) F(\theta q),
\end{aligned}
$$

and the first-order partial derivative of $\pi_{\mathrm{Su}}(Q)$ in (2) is

$$
\frac{\partial \pi_{\mathrm{Su}}(Q)}{\partial Q}=\left(w+\eta_{0}+\tau_{\mathrm{Su}}-c\right)-\left(w+\eta_{0}+\tau_{\mathrm{Su}}-s_{\mathrm{Su}}\right) F(Q) .
$$

The necessary condition for $q$ to be optimal is $\partial \pi_{\mathrm{Re}}(q) / \partial q=0$. However, the apparent expression of optimal order quantity $q_{c}^{*}$ cannot be obtained using (3). In the mix mode, if optimal proportion $\theta^{*}$ is confirmed, then $q_{c}^{*}$ can be calculated through a numerical method based on (3). Furthermore, (4) shows that the second-order partial derivative of $\pi_{\mathrm{Su}}(Q)$ on $Q$ is negative; that is, $\partial^{2} \pi_{\mathrm{Su}}(Q) / \partial Q^{2}=-\left(w+\eta_{0}+\tau_{\mathrm{Su}}-s_{\mathrm{Su}}\right) f(Q)<$ 0 . Thus, the unique optimal production can be obtained by

$$
Q_{c}^{*}=F^{-1}\left(\frac{w+\eta_{0}+\tau_{\mathrm{Su}}-c}{w+\eta_{0}+\tau_{\mathrm{Su}}-s_{\mathrm{Su}}}\right) .
$$

Substituting $q_{c}^{*}$ and $Q_{c}^{*}$ into (1) and (2), the following optimal profit is obtained for the e-retailer and the supplier, respectively:

$$
\begin{aligned}
\left.\pi_{\mathrm{Su}}\left(Q_{c}^{*}\right)\right|_{q=q_{c}^{*}}= & -\eta_{0} \cdot \theta q_{c}^{*}+\left(w+\eta_{0}-c+\tau_{\mathrm{Su}}\right) Q_{c}^{*} \\
& -\left(w-2 s_{\mathrm{Su}}+\eta_{0}\right) \int_{\theta q_{c}^{*}}^{q_{c}^{*}} F(x) d x \\
& -\left(w-s_{\mathrm{Su}}+\eta_{0}\right) \int_{q_{c}^{*}}^{\mathrm{Q}_{c}^{*}} F(x) d x \\
& -\tau_{\mathrm{Su}} \int_{0}^{Q_{c}^{*}} F(x) d x-\tau_{\mathrm{Su}} \mu, \\
\left.\pi_{\mathrm{Re}}\left(q_{c}^{*}\right)\right|_{\mathrm{Q}=Q_{c}^{*}=} & \left(\eta_{0}-v-\delta\right) \cdot \theta q_{c}^{*} \\
& +\left(p+\delta+\tau_{\mathrm{Re}}-w-\eta_{0}\right) Q_{c}^{*} \\
& +\left(s_{\mathrm{Re}}-p\right) \int_{0}^{\theta q_{c}^{*}} F(x) d x \\
& +\left[p+\delta-\left(w-s_{S u}+\eta_{0}\right)\right] \int_{\theta q_{c}^{*}}^{q_{c}^{*}} F(x) d x \\
& -\left[p+\delta-\left(w+\eta_{0}\right)\right] \int_{q_{c}^{*}}^{\mathrm{Q}_{c}^{*}} F(x) d x \\
& -\left[x(x) d x-\tau_{\mathrm{Re}} \mu .\right. \\
\mathrm{Q}_{c}^{*} & \\
& \\
& \\
& \\
&
\end{aligned}
$$

The mix mode in this study is the business mode employed when $0 \leq \theta \leq 1$. Our definition indicates that the FTs chain adopts the traditional mode when $\theta=1$ and adopts the dropshipping mode when $\theta=0$. Both degradation cases were found in the mix mode. To further study the mix mode we discuss two special cases.

3.3.1. Traditional Mode $(\theta=1)$. When $\theta=1$, the e-retailer adopts the traditional mode in which he stores all inventory by himself. In this case, the e-retailer orders $q$ units from the supplier and stores these units in his own warehouse. If the demand exceeds the e-retailer's inventory, he will then forward the demand to the supplier. Therefore, the e-retailer's profit function is

$$
\begin{aligned}
\left.\pi_{\mathrm{Re}}(q)\right|_{\theta=1}= & p E \min (x, q) \\
& +\left[p+\delta-\left(w+\eta_{0}\right)\right] E \min \left(Q-q,(x-q)^{+}\right) \\
& +s_{\operatorname{Re}} E(q-x)^{+}-\tau_{\mathrm{Re}} E(x-Q)^{+}-(w+v) q .
\end{aligned}
$$


The supplier's profit function is

$$
\begin{aligned}
\left.\pi_{\mathrm{Su}}(Q)\right|_{\theta=1}= & w q+\left(w+\eta_{0}\right) E \min \left(Q-q,(x-q)^{+}\right) \\
& +s_{\mathrm{Su}} E(Q-\max (x, q))^{+}-c Q \\
& -\tau_{\mathrm{Su}} E(x-Q)^{+} .
\end{aligned}
$$

To achieve their respective optimal profits, the e-retailer determines order quantity $q$ (i.e., e-retailer inventory), while the supplier determines production Q. A noncooperative, static game is played between the e-retailer and the supplier. Thus, the necessary condition for optimal $q$ and $Q$ is given by

$$
\begin{aligned}
& \frac{\left.\partial \pi_{\mathrm{Re}}(q)\right|_{\theta=1}}{\partial q}=0, \\
& \frac{\left.\partial \pi_{\mathrm{Su}}(Q)\right|_{\theta=1}}{\partial Q}=0 .
\end{aligned}
$$

The optimal $q$ and $Q$ are as follows:

$$
\begin{gathered}
\left.q^{*}\right|_{\theta=1}=F^{-1}\left(\frac{\eta_{0}-v-\delta}{w+\eta_{0}-s_{\mathrm{Re}}-\delta}\right), \\
\left.Q^{*}\right|_{\theta=1}=F^{-1}\left(\frac{w+\eta_{0}+\tau_{\mathrm{Su}}-c}{w+\eta_{0}+\tau_{\mathrm{Su}}-s_{\mathrm{Su}}}\right) .
\end{gathered}
$$

Furthermore, we obtain $\left.\partial^{2} \pi_{\mathrm{Re}}(q)\right|_{\theta=1} / \partial q^{2}<0$ and $\left.\partial^{2} \pi_{\mathrm{Su}}(Q)\right|_{\theta=1} / \partial Q^{2}<0$ based on the assumption $\left(0<s_{\mathrm{Re}}, s_{\mathrm{Su}}\right.$ $\left.<c<w<w+\eta_{0}<p<p+\delta\right)$. Therefore, the optimal profit for the e-retailer and the supplier is given by

$$
\begin{aligned}
\left.\pi_{\mathrm{Re}}\left(q^{*}\right)\right|_{\theta=1, \mathrm{Q}=\mathrm{Q}^{*}}= & \left(\eta_{0}-v-\delta\right) q^{*} \\
& +\left(p+\delta+\tau_{\mathrm{Re}}-w-\eta_{0}\right) \mathrm{Q}^{*} \\
& +\left(s_{\mathrm{Re}}-p\right) \int_{0}^{q^{*}} F(x) d x \\
& -\left(p+\delta-w-\eta_{0}\right) \int_{q^{*}}^{\mathrm{Q}^{*}} F(x) d x \\
& -\tau_{\mathrm{Re}} \int_{0}^{\mathrm{Q}^{*}} F(x) d x-\tau_{\mathrm{Re}} \mu, \\
\left.\pi_{\mathrm{Su}}\left(Q^{*}\right)\right|_{\theta=1, q=q^{*}}= & w q^{*}-c Q^{*}+s_{\mathrm{Su}} \int_{q^{*}}^{\mathrm{Q}^{*}} F(x) d x \\
& +\tau_{\mathrm{Su}} \int_{0}^{\mathrm{Q}^{*}}[1-F(x)] d x \\
& +\left(w+\eta_{0}\right) \int_{q^{*}}^{\mathrm{Q}^{*}}[1-F(x)] d x-\tau_{\mathrm{Su}} \mu,
\end{aligned}
$$

where $q^{*}$ denotes $\left.q^{*}\right|_{\theta=1}$ and $\left.Q^{*} \operatorname{denotes} Q^{*}\right|_{\theta=1}$.

3.3.2. Drop-Shipping Mode $(\theta=0)$. When $\theta=0$, the e-retailer does not store any goods with him and adopts the dropshipping mode. In this mode, the e-retailer is faced with market demand directly and only decides on order quantity $q$. The supplier assumes the demand uncertainty risk and makes his own decision on optimal production $Q^{*}$. Hence, the profits of the e-retailer and the supplier are as follows, respectively:

$$
\begin{aligned}
\left.\pi_{\mathrm{Re}}(q)\right|_{\theta=0}= & {\left[p+\delta-\left(w-s_{\mathrm{Su}}+\eta_{0}\right)\right] E \min (q, x) } \\
& +\left[p+\delta-\left(w+\eta_{0}\right)\right] E \min (Q-q,(x) \\
& -s_{\mathrm{Su}} q-\tau_{\mathrm{Re}} E(x-Q)^{+}, \\
\left.\pi_{\mathrm{Su}}(Q)\right|_{\theta=0}= & s_{\mathrm{Su}} q+\left(w-s_{\mathrm{Su}}+\eta_{0}\right) E \min (q, x) \\
& +\left(w+\eta_{0}\right) E \min \left(Q-q,(x-q)^{+}\right) \\
& +s_{\mathrm{Su}} E(Q-\max (x, q))^{+} \\
& -c Q-\tau_{\mathrm{Su}} E(x-Q)^{+} .
\end{aligned}
$$$$
+\left[p+\delta-\left(w+\eta_{0}\right)\right] E \min \left(Q-q,(x-q)^{+}\right)
$$

The necessary condition for $Q$ to be optimal is $\left.\partial \pi_{\mathrm{Su}}(Q)\right|_{\theta=0} / \partial Q=0$. Furthermore, given that $\left.\partial^{2} \pi_{\mathrm{Su}}(Q)\right|_{\theta=0} /$ $\partial Q^{2}<0$, the optimal production can be calculated as

$$
\left.Q^{*}\right|_{\theta=0}=F^{-1}\left(\frac{w+\eta_{0}+\tau_{\mathrm{Su}}-c}{w+\eta_{0}+\tau_{\mathrm{Su}}-s_{\mathrm{Su}}}\right) \text {. }
$$

Similarly, let $\left.\partial \pi_{\operatorname{Re}}(q)\right|_{\theta=0} / \partial q=0$; we obtain

$$
-s_{\mathrm{Su}} \cdot F(q)=0
$$

For any $q$ in the domain, namely, $\forall q \in[0,+\infty)$, we have $F(q) \geq 0$. Furthermore, we have $s_{\mathrm{Su}}>0$ based on our assumption $\left(0<s_{\mathrm{Re}}, s_{\mathrm{Su}}<c\right)$. Hence, (18) holds if and only if $q=0$ :

$$
\left.q^{*}\right|_{\theta=0}=0 \text {. }
$$

Hence, when the e-retailer adopts the drop-shipping mode, he does not need to order any goods in advance.

Substituting (17) and (19) into (16) and (15), respectively, and rearranging the equations yield

$$
\begin{aligned}
\pi_{\mathrm{Su}} & \left.\left(Q^{*}\right)\right|_{\theta=0, q^{*}=0} \\
= & \left(w+\eta_{0}+\tau_{\mathrm{Su}}-c\right) Q^{*} \\
& \quad-\left(w+\eta_{0}+\tau_{\mathrm{Su}}-s_{\mathrm{Su}}\right) \int_{0}^{Q^{*}} F(x) d x-\tau_{\mathrm{Su}} \mu, \\
\left.\pi_{\mathrm{Re}}\left(q^{*}=0\right)\right|_{\theta=0, \mathrm{Q}=\mathrm{Q}^{*}} & \\
= & \left(p+\delta+\tau_{\mathrm{Re}}-w-\eta_{0}\right) \int_{0}^{\mathrm{Q}^{*}}[1-F(x)] d x-\tau_{\mathrm{Re}} \mu .
\end{aligned}
$$

Through the mix mode, we aim to improve both the eretailer and supplier profits (i.e., Pareto improvement). Before conducting an in-depth study of the mix mode, we examine the variations in the profit resulting from each mode. 
3.4. Comparative Analysis. We compare and analyze profit variation from the traditional mode to the drop-shipping mode. From (5), (12), and (17), we observe that the supplier's optimal production is the same regardless of the value of $\theta$. For simplicity, we denote the optimal production of the supplier by $Q^{*}$. This result contributes to the following analysis.

\subsubsection{From Traditional Mode to Drop-Shipping Mode}

(i) Profit Change of the E-Retailer. Based on (13) and (21), we obtain

$$
\begin{aligned}
\Delta_{\mathrm{Re}}= & v q^{*}+\left(p-s_{\mathrm{Re}}\right) \int_{0}^{q^{*}} F(x) d x \\
& +(p-w)\left[\int_{q^{*}}^{\mathrm{Q}^{*}} F(x) d x-\int_{0}^{\mathrm{Q}^{*}} F(x) d x\right] \\
& +\left(\delta-\eta_{0}\right)\left[q^{*}+\int_{q^{*}}^{\mathrm{Q}^{*}} F(x) d x-\int_{0}^{\mathrm{Q}^{*}} F(x) d x\right],
\end{aligned}
$$

where $\Delta_{\mathrm{Re}}=\left.\pi_{\mathrm{Re}}\left(q^{*}=0\right)\right|_{\theta=0, \mathrm{Q}=\mathrm{Q}^{*}}-\left.\pi_{\mathrm{Re}}\left(q^{*}\right)\right|_{\theta=1, \mathrm{Q}=\mathrm{Q}^{*}}$ represents the e-retailer's profit margin. The drop-shipping mode brings more profit to the e-retailer compared with the traditional mode when $\Delta_{\mathrm{Re}}>0$. Therefore, Theorem 1 holds.

Theorem 1. (1) The sufficient and necessary condition for $\Delta_{R e}>0$ is

$$
\begin{aligned}
\delta-\eta_{0}> & -\left(v q^{*}+\left(p-s_{R e}\right) \int_{0}^{q^{*}} F(x) d x\right. \\
& \left.+(p-w)\left[\int_{q^{*}}^{Q^{*}} F(x) d x-\int_{0}^{Q^{*}} F(x) d x\right]\right) \\
& \times\left(q^{*}+\int_{q^{*}}^{Q^{*}} F(x) d x-\int_{0}^{Q^{*}} F(x) d x\right)^{-1} .
\end{aligned}
$$

(2) One sufficient condition for $\Delta_{R e}>0$ is

$$
\delta>\eta_{0}
$$

(3) When $Q^{*}>q^{*}$, one obtains $\Delta_{R e}>0$ if the parameters satisfy

$$
\delta-\eta_{0}>-\frac{v q^{*}+\left(w-s_{R e}\right) \int_{0}^{q^{*}} F(x) d x}{\int_{0}^{q^{*}}[1-F(x)] d x} .
$$

Proof of Theorem 1. (a) Given (22), let $\Delta_{\mathrm{Re}}>0$; hence, we can easily achieve the sufficient and necessary condition of the eretailer's expected profit improvement.

(b) In either $Q^{*}>q^{*}$ or $Q^{*}<q^{*}$, we obtain

$$
\begin{aligned}
\Delta_{\mathrm{Re}}= & v q^{*}+\left(w-s_{\mathrm{Re}}\right) \int_{0}^{q^{*}} F(x) d x \\
& +\left(\delta-\eta_{0}\right) \int_{0}^{q^{*}}[1-F(x)] d x .
\end{aligned}
$$

From this equation, if $\delta-\eta_{0}>0, \Delta_{\mathrm{Re}}>0$ will be true.

(c) When $Q^{*}>q^{*}$, we have $\Delta_{\operatorname{Re}}=\left(v+\delta-\eta_{0}\right) q^{*}+(w+$ $\left.\eta_{0}-s_{\mathrm{Re}}-\delta\right) \int_{0}^{q^{*}} F(x) d x$.

One has $w>s_{\mathrm{Su}}$, so let $\Delta_{\mathrm{Re}}>0$; we will obtain (3).

(ii) Profit Change of the Supplier. Define $\Delta_{\mathrm{Su}}=$ $\left.\pi_{\mathrm{Su}}\left(Q^{*}\right)\right|_{\theta=0, q^{*}=0}-\left.\pi_{\mathrm{Su}}\left(Q^{*}\right)\right|_{\theta=1, q=q^{*}}$ and $\Delta_{\mathrm{Su}}$ expresses supplier profit change from the traditional mode $(\theta=1)$ to the dropshipping mode $(\theta=0)$. Based on (14) and (20), we have

$$
\Delta_{\mathrm{Su}}=\eta_{0} q^{*}+\left(w+\eta_{0}-s_{\mathrm{Su}}\right)\left[\int_{q^{*}}^{\mathrm{Q}^{*}} F(x) d x-\int_{0}^{\mathrm{Q}^{*}} F(x) d x\right] .
$$

By analyzing (27), we obtain Theorem 2.

Theorem 2. When the supplier adopts the traditional to dropshipping mode

(1) the sufficient and necessary condition of improvement for the supplier's expected profit is

$$
\eta_{0}>\left(\eta_{0}\right)_{\min }=\frac{\left(w-s_{S u}\right)\left[\int_{0}^{Q^{*}} F(x) d x-\int_{q^{*}}^{Q^{*}} F(x) d x\right]}{q^{*}-\int_{0}^{Q^{*}} F(x) d x+\int_{q^{*}}^{Q^{*}} F(x) d x}
$$

(2) one of the sufficient conditions is

$$
\eta_{0}>\frac{\left(w-s_{S u}\right) \int_{0}^{q^{*}} F(x) d x}{\int_{0}^{q^{*}}[1-F(x)] d x} .
$$

Proof of Theorem 2. (a) By rewriting (27) and assuming that $\Delta_{\text {Su }}>0$, we can easily achieve the lower bound of net risk compensation.

(b) When $Q^{*}>q^{*}$, we rearrange the expression of $\Delta_{\mathrm{Su}}$ and obtain

$$
\Delta_{\mathrm{Su}}=\eta_{0} \int_{0}^{q^{*}}[1-F(x)] d x-\left(w-s_{\mathrm{Su}}\right) \int_{0}^{q^{*}} F(x) d x .
$$

Given that $w>s_{\mathrm{Su}}$ and letting $\Delta_{\mathrm{Su}}>0$, we arrive at our conclusion. When $Q^{*}<q^{*}$, the same result can be obtained.

The mix mode is a combination of the traditional and drop-shipping modes. Under specific conditions (see Theorems 1 and 2), the e-retailer and the supplier can augment their profit by shifting from the traditional to the dropshipping mode. Furthermore, in the mix mode, both the eretailer and the supplier share the inventory risk. Hence, the mix mode overcomes the weakness of each business mode applied in sales promotion activities. 
TABLE 1: Three scenarios of the FTs chain under the mix mode.

\begin{tabular}{llr}
\hline & Description & Condition \\
\hline Scenario 1 & Pareto improvement achieved & $\delta>\eta_{0}>\frac{\left(w-s_{\mathrm{Su}}\right) \int_{0}^{q^{*}} F(x) d x}{\int_{0}^{q^{*}}[1-F(x)] d x}$ \\
Scenario 2 & Overall profit of the FTs chain ascends but Pareto improvement cannot be guaranteed & Both $Q^{*}>q^{*}$ and $s_{\mathrm{Su}}<s_{\mathrm{Re}}$ \\
Scenario 3 & Improved profit of the FTs chain cannot be guaranteed & Either $Q^{*} \leq q^{*}$ or $s_{\mathrm{Su}} \geq s_{\mathrm{Re}}$ \\
\hline
\end{tabular}

3.4.2. Profit Improvement. The drop-shipping mode fits the ecommerce environment, particularly for FTs chains which are strongly influenced by timeliness and seasonality. Netessine et al. $[14,16]$ identified the condition under which the dropshipping mode is more effective than the traditional mode. Given that both traditional and drop-shipping modes are special cases of the proposed mix mode, the mix mode helps us analyze FTs chains in general. For the FTs chain, three scenarios may exist, which will be discussed below.

(i) Both the e-retailer and the supplier achieved an improved profit. In this scenario, the drop-shipping mode is a better choice than the traditional mode. This scenario requires that both $\left.\pi_{\mathrm{Su}}\left(Q^{*}\right)\right|_{\theta=0, q^{*}=0}>\left.\pi_{\mathrm{Su}}\left(Q^{*}\right)\right|_{\theta=1, q=q^{*}}$ and $\left.\pi_{\mathrm{Re}}\left(q^{*}=0\right)\right|_{\theta=0, \mathrm{Q}=\mathrm{Q}^{*}}>\left.\pi_{\mathrm{Re}}\left(q^{*}\right)\right|_{\theta=1, \mathrm{Q}=\mathrm{Q}^{*}}$. Based on Theorems 1 and 2, we obtain Theorem 3.

Theorem 3. Both the e-retailer and the supplier gain an increased profit if the parameters satisfy

$$
\delta>\eta_{0}>\frac{\left(w-s_{S u}\right) \int_{0}^{q^{*}} F(x) d x}{\int_{0}^{q^{*}}[1-F(x)] d x} .
$$

(ii) The overall profit of the FTs chain increases, but only the profit of one party improves (i.e., either the e-retailer or the supplier). In this case, we employ a profit allocation strategy to realize Pareto improvement. Hence, we have to determine the conditions in which overall profit can increase. Based on (22) and (27), we obtain

$$
\begin{aligned}
\Delta_{\text {chain }}= & \Delta_{\mathrm{Re}}+\Delta_{\mathrm{Su}} \\
= & (v+\delta) q^{*}+\left(p-s_{\mathrm{Re}}\right) \int_{0}^{q^{*}} F(x) d x \\
& -\left(p+\delta-s_{\mathrm{Su}}\right)\left[\int_{0}^{Q^{*}} F(x) d x-\int_{q^{*}}^{Q^{*}} F(x) d x\right] .
\end{aligned}
$$

Based on (32), let $\Delta_{\text {chain }}>0$, and we obtain Theorem 4 .

Theorem 4. The overall profit of the FTs chain improves when both conditions $Q^{*}>q^{*}$ and $\delta>-\left(\left(s_{S u}-s_{R e}\right) \int_{0}^{q^{*}} F(x) d x+\right.$ $\left.v q^{*}\right) /\left(\int_{0}^{q^{*}}[1-F(x)] d x\right)$ hold.

Theorem 4 is difficult to distinguish; thus, we present a relatively simple Corollary 5; thus, (32) is simply distinguished by Corollary 5 .
Corollary 5. If $Q^{*}>q^{*}$ and $s_{S u}<s_{R e}$, then $\Delta_{\text {chain }}>0$.

This corollary is easily derived from Theorem 4. Corollary 5 has a practical significance for the FTs supply chain. $Q^{*}>q^{*}$ implies that the supplier's optimal production is larger than the optimal order quantity of the e-retailer, which is consistent with reality. By the end of the demand season, the e-retailer can easily dispose of unsold items using sales promotions considering that he has direct contact with customers. However, when the supplier has unsold items, he cannot easily dispose of these items for he lacks a distribution channel. Hence, the salvage value of unsold items is higher for the e-retailer than it is for the supplier, namely, $s_{\mathrm{Su}}<s_{\mathrm{Re}}$.

(iii) When the conditions of Corollary 5 do not hold, the profit improvement of the entire FTs chain cannot be guaranteed. However, this situation is rarely observed and is thus not discussed in detail. The results of the three scenarios are listed in Table 1.

Certain types of FTs usually have short life cycles. Hence, during its life cycle, the e-retailer and the supplier will adopt sales promotion activities to stimulate customer demand. Neither the traditional nor the drop-shipping mode is appropriate for the demand in this situation. In the traditional mode, e-retailer undertakes all the risk, whereas the supplier undertakes all the risk in the drop-shipping mode. In cases with great demand uncertainty, neither business mode can satisfy both parties. If both parties want to satisfy customer demand without taking too much risk, then the mix mode is the best option. This risk sharing strategy helps both parties in the FTs chain to alleviate risk, particularly for demand peak or existing sales promotion activities.

\section{Decisions under Demand Fluctuation}

The timeliness or seasonality of the fashion business results in the common occurrence of demand fluctuation, which usually leads to unpredictable demand. Hence, the total FTs chain cannot achieve the optimal profit or meet the market demand. In this section, we first describe the demand fluctuation in the fashion industry with sales promotion activities or demand season peaks. Then, we study the application of the mix mode in this situation.

4.1. Description of Fashion Demand. The most evident characteristic of FTs is its short demand season. Customers usually make purchase decisions at the beginning of a sale season. For example, a customer often buys winter clothing before winter arrives $[25,26]$ or buys a team jersey before the 


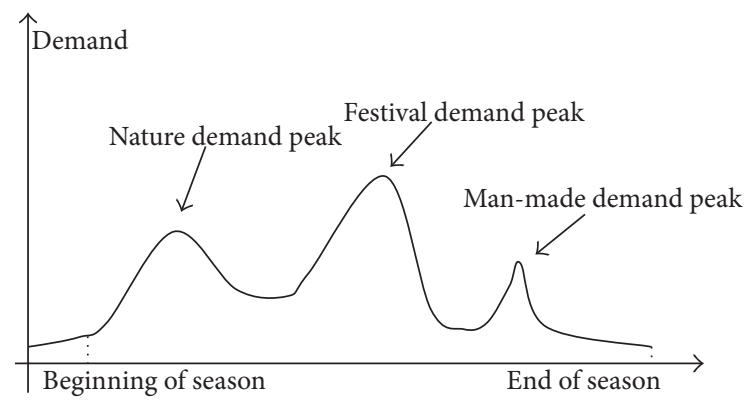

Figure 2: Fashion demand changes in a season.

NBA season finishes. Hence, in a fashion demand season, this occurrence is the first demand peak, denoted by the nature demand peak $[27,28]$. During the fashion demand season, another demand peak is observed when another important event occurs (e.g., Christmas Day or NBA Finals) [17, 18]. This type of demand peak is the festival demand peak. When a large number of unsold items remain at the end of the fashion demand season, a sales promotion activity will be conducted to alleviate inventory risk. This is the third demand peak, the man-made demand peak [29]. In conclusion, three demand peaks are usually observed in a demand season (see Figure 2).

As shown in Figure 2, the different demand peaks have different distribution parameters (i.e., expected value and standard deviation). The nature demand peak usually has medium expected value $\mu$ and a small standard deviation $\sigma$ (i.e., the demand persists longer than other peaks). The rise of the nature demand peak requires more time compared with other peaks. However, the emergence of festival demand peak is uncertain; that is, this peak is not necessarily caused by the festival factor. For example, a major sports event may influence the sales of T-shirts with the participating teams' names. If the festival demand peak exists, then this peak will have a large $\mu$ because this peak is under the dual influence of natural demand and festival shock. A sales promotion activity does not last very long; thus, the man-made demand peak usually has a small $\mu$ and a big $\sigma$. Understanding the changing process of fashion demand is conducive for forecasting the fashion demand to help members of the FTs chain to determine the proper business mode.

Based on the assumption, demand $x$ is a random variable with a known probability density function. Owing to the existence of a demand peak, $x$ is too difficult (if possible) to describe. For products with short life cycles, common forecast models are not applicable because these often lack sales data for the prediction [30]. The subjective prediction and experience information of the sales staff improve the accuracy of demand prediction. In the succeeding section, we include estimate information to our mix mode to improve practicability.

We define fashion demand as $x \sim F(\mu, \sigma)$. In case when there are factors that may affect the fashion demand, we will add information to the demand model. Defining the information as $\psi$, we obtain

$$
x \mid \psi \sim F\left(\mu^{\prime}, \sigma^{\prime}\right) .
$$

Here $\psi$ represents an event or the experience of the sales staff. For simplicity, we consider that $\psi$ affects mean $\mu$ and variance $\sigma^{2}$ of demand $x$. Thus, we denote the new parameters by $\mu^{\prime}$ and $\sigma^{\prime}$. If the event has a positive influence on demand, then we will increase the mean and vice versa. If we cannot verify whether the event has a positive or negative influence on demand, then we increase the variance. Moreover, the duration of the event likewise affects the values of the parameters. We carefully evaluate the effect of each event.

4.2. Adjustment in the Mix Mode. The traditional mode $(\theta=$ 1 ) and the drop-shipping mode $(\theta=0)$ are not fit for situations with drastic demand fluctuations. However, the parameter $\theta$ can be adjusted in the mix mode: adjusting $\theta$ implies that the e-retailer has different fashion inventory level. Hence, the e-retailer and the supplier share the risk caused by the demand fluctuation in a mix mode.

In (1) and (2), we consider $\theta$ as a parameter, and, thus, we cannot directly take the derivative with respect to $\theta$. Consequently, we build another loss model under drastic demand fluctuation.

The e-retailer encounters considerable uncertainty and fluctuation when a demand peak emerges. To reduce the risk and meet the demand, the mix mode is the best choice. In the mix mode, the e-retailer decides the proportion of the quantity used for in-house inventory $\theta$. Within the part of $\theta$ [i.e., $\min (x, \theta q)]$, the FTs chain operates in the traditional mode; the e-retailer is in control of the service. Within the part of $1-\theta$ [i.e., $\left.\min \left((1-\theta) q,(x-\theta q)^{+}\right)\right]$, the e-retailer adopts the drop-shipping mode in which he gives up control of the service; hence, a delay phenomenon may occur. Thus, we obtain

$$
\begin{aligned}
H(\theta, x \mid \psi)= & h_{1} E \min (x, \theta q) \\
+ & +h_{2}\left[E \min \left((1-\theta) q,(x-\theta q)^{+}\right)\right. \\
& \left.\quad+E \min \left(Q-q,(x-q)^{+}\right)\right] \\
& +h_{3} E(x-q)^{+},
\end{aligned}
$$

where $H(\theta, x \mid \psi)$ denotes the loss caused by inadequate service and $h$ indicates the service loss coefficient. In the mix mode, customers are unaware of the business mode but are perceptive of the service they receive [31]. If the dropshipping mode is adopted, then the e-retailer has to deal with the customers' complaints even if order cancellation is caused by supplier's failure to deliver the goods in a timely manner. Therefore, $h_{2}>h_{1}$. The loss coefficient $h_{3}$ is the largest for the shortage part $(x-q)^{+}$, and, thus, we have $h_{1}<h_{2}<h_{3}$. $x \mid \psi$ denotes fashion demand with information $\psi \cdot q$ and $Q$ lie on (3) and (5), namely, $q_{c}^{*}$ and $Q_{c}^{*}$, respectively. Thus, the e-retailer decides the $\theta$ value after the optimal order $q_{c}^{*}$ is determined. Then, we have

$$
\begin{aligned}
G(\theta, x \mid \psi)= & \left(w+v-s_{\mathrm{Re}}\right) E(\theta q-x)^{+} \\
& +s_{\mathrm{Su}} E(q-\max (x, \theta q))^{+},
\end{aligned}
$$

where $G(\theta, x \mid \psi)$ denotes the loss caused by unsold items. If $x<\theta q$, then the difference between the cost and salvage value 
TABle 2: Coefficient default values.

\begin{tabular}{cccccccccccc}
\hline$w$ & $v$ & $\delta$ & $\eta_{0}$ & $s_{\mathrm{Re}}$ & $s_{\mathrm{Su}}$ & $h_{1}$ & $h_{2}$ & $c$ & $p$ & $\tau_{\mathrm{Su}}$ & $\tau_{\mathrm{Re}}$ \\
\hline 100 & 5 & 1 & 65 & 35 & 18 & 5 & 30 & 45 & 250 & 60 & 80 \\
\hline
\end{tabular}

$\left(w+v-s_{\mathrm{Re}}\right)$ is the implicit loss of the e-retailer. If $(1-\theta) q$ is not completely sold out by the end of the demand season, then the deposit $s_{\mathrm{Su}}$ for the surplus (i.e., $\left.(q-\max (x, \theta q))^{+}\right)$ results in a loss as well.

Based on (34) and (35), the e-retailer's loss is as follows:

$$
\begin{aligned}
L= & H(\theta, x \mid \psi)+G(\theta, x \mid \psi) \\
= & h_{1} E \min \left(x, \theta q^{*}\right) \\
& +h_{2}\left[E \min \left((1-\theta) q^{*},\left(x-\theta q^{*}\right)^{+}\right)\right. \\
& \left.\quad+E \min \left(Q^{*}-q^{*},\left(x-q^{*}\right)^{+}\right)\right] \\
& +h_{3} E\left(x-q^{*}\right)^{+}+v E\left(\theta q^{*}-x\right)^{+} \\
& +s_{\mathrm{Su}} E\left(q^{*}-\max \left(x, \theta q^{*}\right)\right)^{+} .
\end{aligned}
$$

The first-order partial derivative of $L$ is

$$
\frac{\partial L}{\partial \theta}=q^{*}\left[h_{1}-h_{2}+\left(h_{2}-h_{1}+w+v-s_{\mathrm{Re}}-s_{\mathrm{Su}}\right) F\left(\theta q^{*}\right)\right] \text {. }
$$

Let $\partial L / \partial \theta=0$; we obtain

$$
\theta^{*}=\frac{1}{q^{*}} F^{-1}\left(\frac{h_{2}-h_{1}}{h_{2}-h_{1}+w+v-s_{\mathrm{Re}}-s_{\mathrm{Su}}}\right)
$$

According to the definition of $\theta, F^{-1}\left(\left(h_{2}-h_{1}\right) /\left(h_{2}-h_{1}+\right.\right.$ $\left.\left.w+v-s_{\operatorname{Re}}-s_{\mathrm{Su}}\right)\right)$ is e-retailer optimal inventory level. The e-retailer's optimal inventory level is influenced by $h_{1}, h_{2}, v$, $s_{\mathrm{Su}}$, and the distribution parameters $\left(\mu^{\prime}\right.$ and $\left.\sigma^{\prime}\right)$ of the market demand. Based on (38), the e-retailer can adjust his inventory level using the variations of the parameters. The values of $h_{1}, h_{2}, v$, and $s_{\text {Su }}$ are fixed; hence, the value of $\theta^{*}$ depends on demand distribution $F(\cdot)$. Taking experience information $\left(\mu^{\prime}\right.$ and $\sigma^{\prime}$ ) into consideration, we have a more accurate demand distribution and a proper optimal inventory level. The inventory risk is reasonably shared between the e-retailer and the supplier. Consequently, demand can be achieved, and both parties will attain an improved profit. This conclusion is verified by a numerical study presented in the next section.

\section{Numerical Study and Discussion}

In this section, we provide a numerical study to investigate the tendencies of $\theta^{*}$ under demand fluctuation. We compare the three modes of fashion e-retailer profit under demand fluctuation.

The FTs chain consists of an e-retailer and a supplier (or a fashion manufacturer). Market demand for this particular type follows a normal distribution $N\left(\mu, \sigma^{2}\right)$, where distribution parameter variation implies demand fluctuation. The other coefficients are listed in Table 2.

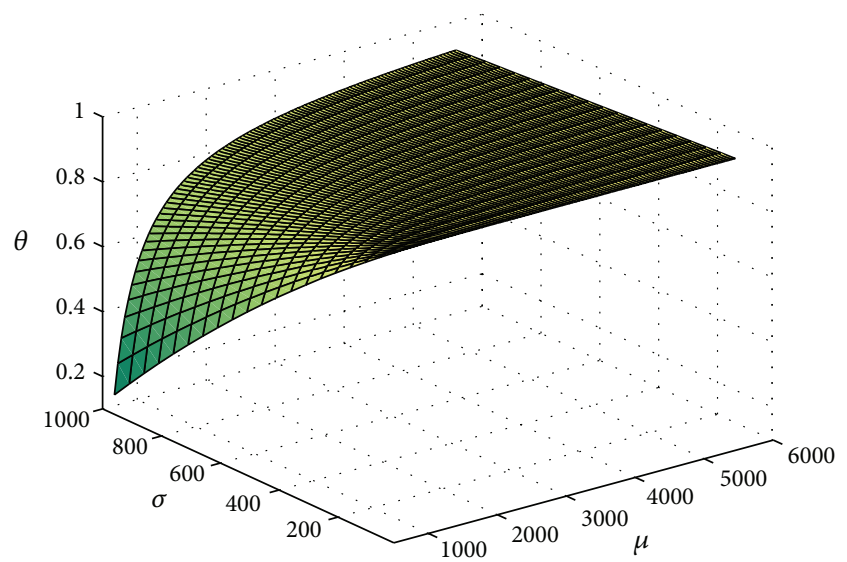

FIGURE 3: The tendency of optimal inventory level.

Using the coefficients in Table 2, we employ Matlab for the numerical simulations. We obtain the optimal inventory level $\theta^{*}$ in mix mode with (38) before comparing the eretailer's profit for the three modes. We have a corresponding $\theta^{*}$ given a demand distribution. The adjustment of $\theta^{*}$ based on demand distribution parameters $\mu$ and $\sigma$ is shown in Figure 3.

Figure 3 demonstrates the influence of demand distribution parameters $(\mu$ and $\sigma$ ) on optimal in-house inventory level $\theta^{*}$. Figure 3 shows that a fixed pair of $\mu$ and $\sigma$ leads to a fixed $\theta^{*}$. To observe the trend of $\theta^{*}$ with a single parameter, we set two special cases: (a) mean $\mu=1000$, standard deviation $\sigma \in[10,1000]$ and (b) $\sigma=100, \mu \in[500,5450]$. The result is shown in Figure 4; these two curves are special cases of Figure 3.

Figure 4 provides two conclusions: (1) when the mean $\mu$ is constant, the proportion $\theta$ monotonically decreases with the standard deviation $\sigma$. More importantly, this relationship is approximately linear, which is consistent with reality. Eretailers prefer to keep inventory at a low level when the demand is uncertain; and (2) when standard deviation is constant, the proportion $\theta$ increases monotonically with mean $\mu$ and growth increase slows down, unable to reach 1 . This relationship indicates that e-retailers will increase their inventory level for profit only if demand expectation increases as well. Otherwise, e-retailers adopt the drop-shipping mode on partial items as long as demand uncertainty exists.

Based on the numerical example above, we obtain optimal proportion $\theta^{*}$. Substituting $\theta^{*}$ into (3), optimal order $q_{c}^{*}$ is obtained through the Newton interpolation method. We then have the retailer's profit under the mix mode with (7). Market demand fluctuation (or uncertainty) primarily reflects on variance; hence, we consider a case where demand mean $\mu$ remains constant, standard deviation changes from 50 to 1000 , and step value is 100 . We express the relationship between profit margin and standard deviation in the 


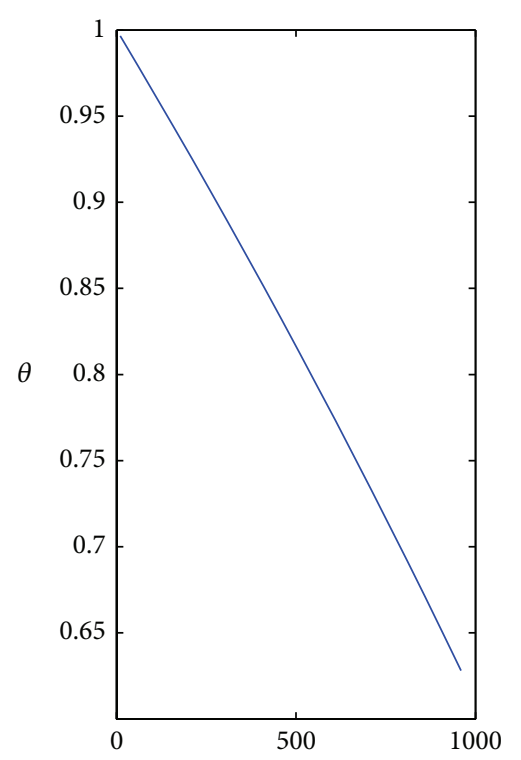

(a) $\mu=1000, \sigma \in[10,1000]$

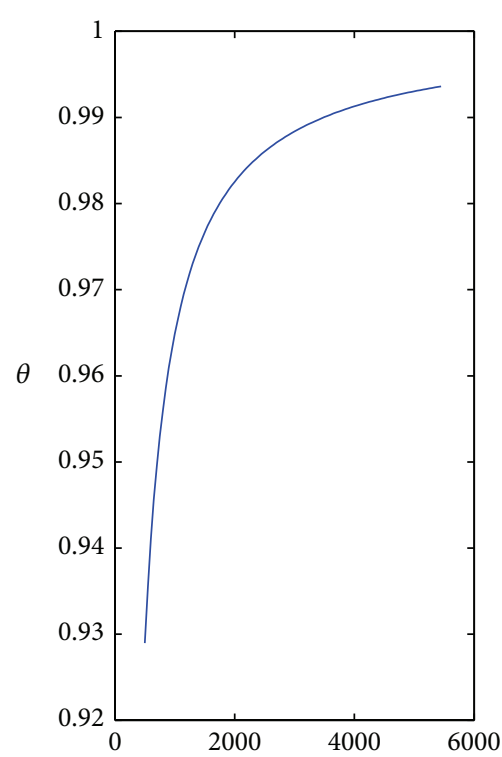

(b) $\mu \in[500,5450], \sigma=100$

FIGURE 4: The tendency of optimal inventory level with a fixed parameter.

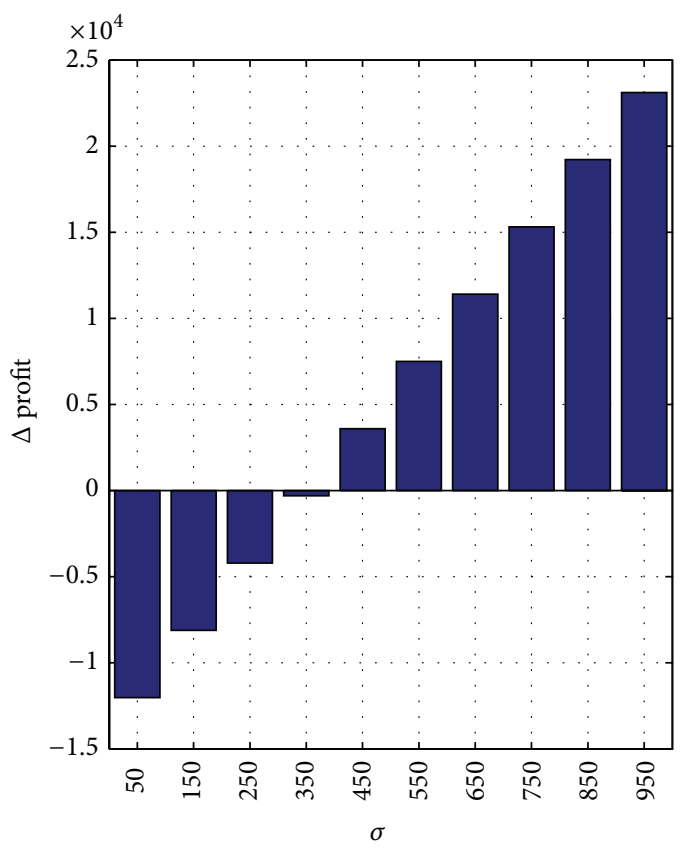

(a) Mix mode versus traditional mode

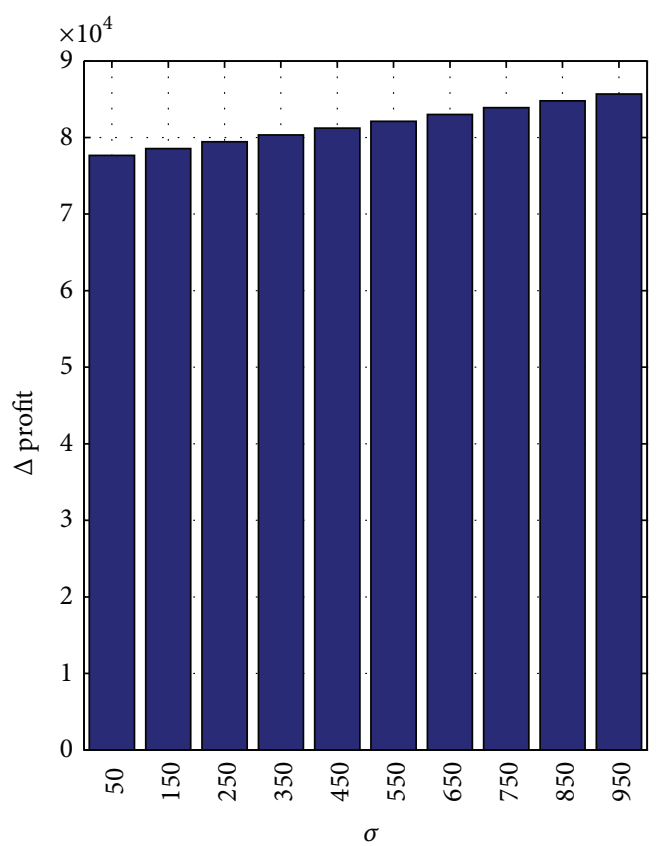

(b) Mix mode versus drop-shipping mode

Figure 5: Variation of profit across the three modes under demand fluctuation.

histogram to clearly demonstrate the profit variation caused by demand fluctuation. The result is shown in Figure 5.

Figure 5 illustrates the relationship between the eretailer's profit variation and the demand fluctuation under different business modes. From Figure 5, we draw the following conclusions: (1) the e-retailer's profit improves as demand fluctuation increases. That is, high risks indicate high rewards; (2) Figure 5(a) shows that the traditional mode is more effective compared with the mix mode when the standard deviation is small. Specifically, the traditional mode is more profitable when the demand fluctuation is small. Hence, when e-retailers are sure about market demand, they will store goods in their own warehouse. (3) When the variance increases to a certain point, the profit resulting from the mix mode surpasses that of the traditional mode. That is, the mix mode is more suitable with drastic demand fluctuations. 
Figure 5(b) shows that profit margin between mix mode and drop-shipping mode is positive. This finding implies that the mix mode is more effective than the drop-shipping mode. In addition, this result shows that the mix mode is more flexible than the drop-shipping mode, particularly during demand fluctuations.

\section{Conclusion}

In this study, we propose a new business mode (i.e., mix mode) for FTs chains in e-commerce environments. A generalized profit model was built to analyze FTs chains comprising one e-retailer and one supplier. The mix mode is a combination of the traditional mode and the dropshipping mode; as such, this mode can transform into the traditional mode when $\theta=1$ or into the drop-shipping mode when $\theta=0$. Altering the value of $\theta$ changes their share in the mix mode. The optimal order quantity and production for these three modes are provided. Notably, the optimal production is identical in all three modes. Likewise, we provide conditions under which FTs chains, along with member profit, can be improved from traditional to dropshipping mode (Table 1). According to our study, Pareto improvement is achieved in Scenario 1 where both e-retailer and supplier profits are improved. In Scenario 2, a profit allocation strategy is designed to achieve Pareto improvement, given that the FTs chain's overall profit has been improved. In Scenario 3, the FTs chain's profit improvement cannot be guaranteed. Nevertheless, Scenario 3 is rare, and thus, a detailed discussion is not provided in this paper.

Based on Corollary 5, we have a slack constraint under which overall profit of the FTs chain improves. More importantly, the conditions $\left(Q^{*}>q^{*}\right.$ and $\left.s_{\mathrm{Su}}<s_{\mathrm{Re}}\right)$ easily hold in reality. It implies that, in most cases, a FTs chain can achieve profit improvement in the process of transformation from traditional mode to drop-shipping mode.

The mix mode adjusts the inventory risk between the two modes. The mix mode is essentially seen as a risk sharing mechanism. If we take the risk of seasonal fashion item into account, then this business mode is suitable for a FTs chain under drastic demand fluctuation. Our study shows that (a) when the demand expected value is constant and fluctuation increases, the e-retailers would lower their inventory proportion and share inventory risk with suppliers to optimize their expected profit. The relationship between inventory proportion and fluctuation is approximately linear in this case; (b) when demand fluctuation is constant and the total demand increases, e-retailers ascend inventory proportion to attain personal profit maximization. However, the ascendant rate decreases with a larger demand fluctuation. In addition, we compare the e-retailer's profit from different modes under drastic demand fluctuation. From Figure 5, we derive the following conclusions: (a) when the demand fluctuation is relatively small, the traditional mode is the most effective business mode for FTs chains and (b) when the demand fluctuation is drastic, the mix mode exceeds both traditional and drop-shipping modes.

In an e-commerce environment, the drop-shipping mode alleviates the inventory risk from e-retailers. However, the drop-shipping mode has lower profitability as compared with the traditional mode. In this study, we propose a mix mode that utilizes both traditional and drop-shipping modes. The drop-shipping part of the mix mode is used to respond to the risk, whereas the traditional part of the mix mode improves on profit making. Considering that FTs chains are seasonal, the proposed mix mode can take full advantage of the demand fluctuation and improve the profit-making ability of FTs chains.

\section{Conflict of Interests}

The authors declare that there is no conflict of interests regarding the publication of this paper.

\section{Acknowledgments}

This work is supported in part by the National Natural Science Foundation of China under Grants nos. 71301154 and 71110107024. The authors would like to thank the referees as well for their valuable time.

\section{References}

[1] Z. Cheng, J. Xiao, K. Xie, and X. Huang, "Optimal product quality of supply chain based on information traceability in fashion and textiles industry: an adverse logistics perspective," Mathematical Problems in Engineering, vol. 2013, Article ID 629363, 13 pages, 2013.

[2] A. Şen, "The US fashion industry: a supply chain review," International Journal of Production Economics, vol. 114, no. 2, pp. 571-593, 2008.

[3] L. G. Sin and R. Purnamasari, "China e-commerce market analysis: forecasting and profiling internet user," Researchers World-Journal of Arts, Science \& Commerce, vol. 2, no. 3, pp. 1-8, 2011.

[4] International Trade Centre (ITC), "The Chinese market for clothing," Technical Paper, ITC, Geneva, Switzerland, 2011.

[5] C. Hong and S. Lian, "Empirical research on international competitiveness of Chinas fashion and textiles industry," Management and Technology of SME, vol. 12, no. 12, pp. 201-203, 2012.

[6] Z. Chen and Z. Zhang, "The analysis of supply chain channel choice on the internet," in Proceedings of the International Conference on Management Science and Engineering (ICMSE '07), pp. 22-27, IEEE, Harbin, China, August 2007.

[7] G. Torkzadeh and G. Dhillon, "Measuring factors that influence the success of internet commerce," Information Systems Research, vol. 13, no. 2, pp. 187-204, 2002.

[8] Y. Aviv, "The effect of collaborative forecasting on supply chain performance," Management Science, vol. 47, no. 10, pp. 13261343, 2001.

[9] F. M. Bass, "A new product growth model for consumer durables," Management Science, vol. 15, no. 5, pp. 215-227, 1969.

[10] F. M. Bass, "Comments on "A new product growth for model consumer durables the bass model'”, Management Science, vol. 50, no. 12, pp. 1833-1840, 2004.

[11] E. Ilicheva, "E-commerce as a gateway to promote and sell fashion," Textiles Eastern Europe, vol. 18, no. 2, pp. 3-4, 2011. 
[12] A. V. Stojanovic, "Virtual boutique-try clothes on-line," in Proceedings of the 5th International Conference on Telecommunications in Modern Satellite, Cable and Broadcasting Service, vol. 2, pp. 802-803, 2001.

[13] A. Ayanso, M. Diaby, and S. K. Nair, "Inventory rationing via drop-shipping in internet retailing: a sensitivity analysis," European Journal of Operational Research, vol. 171, no. 1, pp. 135$152,2006$.

[14] S. Netessine and N. Rudi, "Supply chain choice on the internet," Management Science, vol. 52, no. 6, pp. 844-864, 2006.

[15] J. P. Bailey and E. Rabinovich, "Internet book retailing and supply chain management: an analytical study of inventory location speculation and postponement," Transportation Research Part E: Logistics and Transportation Review, vol. 41, no. 3, pp. 159177, 2005.

[16] T. Randall, S. Netessine, and N. Rudi, "An empirical examination of the decision to invest in fulfillment capabilities: a study of internet retailers," Management Science, vol. 52, no. 4, pp. 567580, 2006.

[17] K. Moutaz, "The evaluation of drop shipping option for ecommerce retailers," Computers \& Industrial Engineering, vol. 41, no. 2, pp. 109-126, 2001.

[18] M. Khouja and A. C. Stylianou, "A (Q, R) inventory model with a drop-shipping option for e-business," Omega, vol. 37, no. 4, pp. 896-908, 2009.

[19] M. Bruce, L. Daly, and N. Towers, "Lean or agile: a solution for supply chain management in the textiles and clothing industry?" International Journal of Operations and Production Management, vol. 24, no. 1-2, pp. 151-170, 2004.

[20] K. L. Donohue, "Efficient supply contracts for Fashion goods with forecast updating and two production modes," Management Science, vol. 46, no. 11, pp. 1397-1411, 2000.

[21] G. Xie, Y. Zhao, M. Jiang, and N. Zhang, "A novel ensemble learning approach for corporate financial distress forecasting in fashion and textiles supply chains," Mathematical Problems in Engineering, vol. 2013, Article ID 493931, 2013.

[22] Z. L. Sun, T. M. Choi, K. F. Au, and Y. Yu, "Sales forecasting using extreme learning machine with applications in fashion retailing," Decision Support Systems, vol. 46, no. 1, pp. 411-419, 2008.

[23] T. M. Choi, Y. Yu, and K. F. Au, "A hybrid SARIMA wavelet transform method for sales forecasting," Decision Support Systems, vol. 51, no. 1, pp. 130-140, 2011.

[24] K.-F. Au, T.-M. Choi, and Y. Yu, "Fashion retail forecasting by evolutionary neural networks," International Journal of Production Economics, vol. 114, no. 2, pp. 615-630, 2008.

[25] V. Srinivasan and C. H. Mason, "Non-linear least squares estimation of new product diffusion models," Marketing Science, vol. 5, no. 2, pp. 169-178, 1986.

[26] P. Nelson, "Information and consumer behavior," The Journal of Political Economy, vol. 78, no. 2, pp. 311-329, 1970.

[27] A. M. Barreiro, "Towards a new system for the fashion industry: the Zara model," Revista Internacional de Sociologia, vol. 66, no. 51, pp. 105-122, 2008.

[28] P. Schiegg, A. L. Soares, A. Garg, R. Roesgen, and V. Stich, "Configuring consumer-demand driven supply networks," in Processes and Foundations for Virtual Organizations: IFIP TC5/WG5.5 4th Working Conference on Virtual Enterprises (PRO-VE'03) October 29-31, 2003, Lugano, Switzerland, vol. 134 of IFIP-The International Federation for Information Processing, pp. 475-481, 2004.
[29] H. J. Peng and M. H. Zhou, "Quantity discount supply chain models with fashion products and uncertain yields," Mathematical Problems in Engineering, vol. 2013, Article ID 895784, 11 pages, 2013.

[30] A. A. Kurawarwala and H. Matsuo, "Forecasting and inventory management of short life-cycle products," Operations Research, vol. 44, no. 1, pp. 131-150, 1996.

[31] X. Gan, S. P. Sethi, and J. Zhou, "Commitment-penalty contracts in drop-shipping supply chains with asymmetric demand information," European Journal of Operational Research, vol. 204, no. 3, pp. 449-462, 2010. 


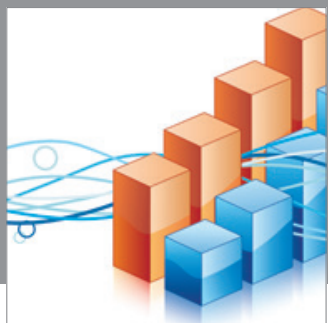

Advances in

Operations Research

mansans

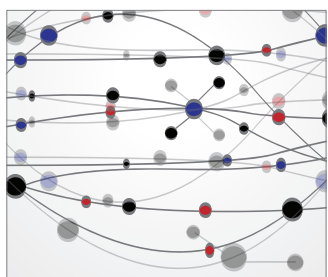

The Scientific World Journal
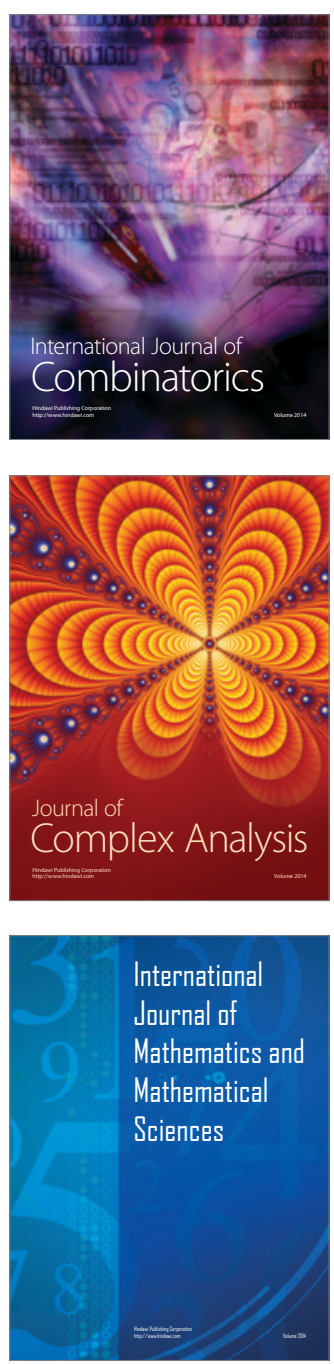
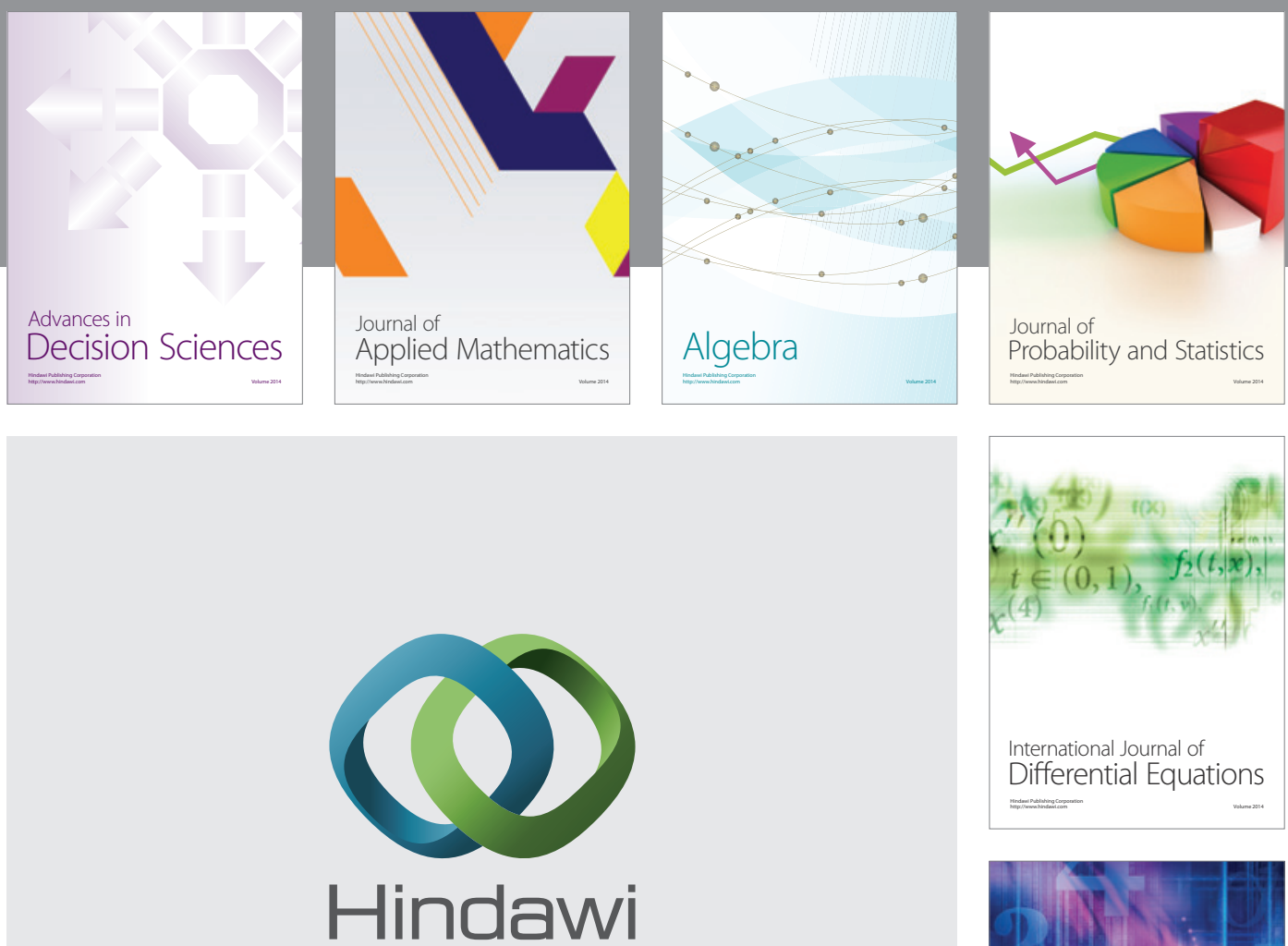

Submit your manuscripts at http://www.hindawi.com
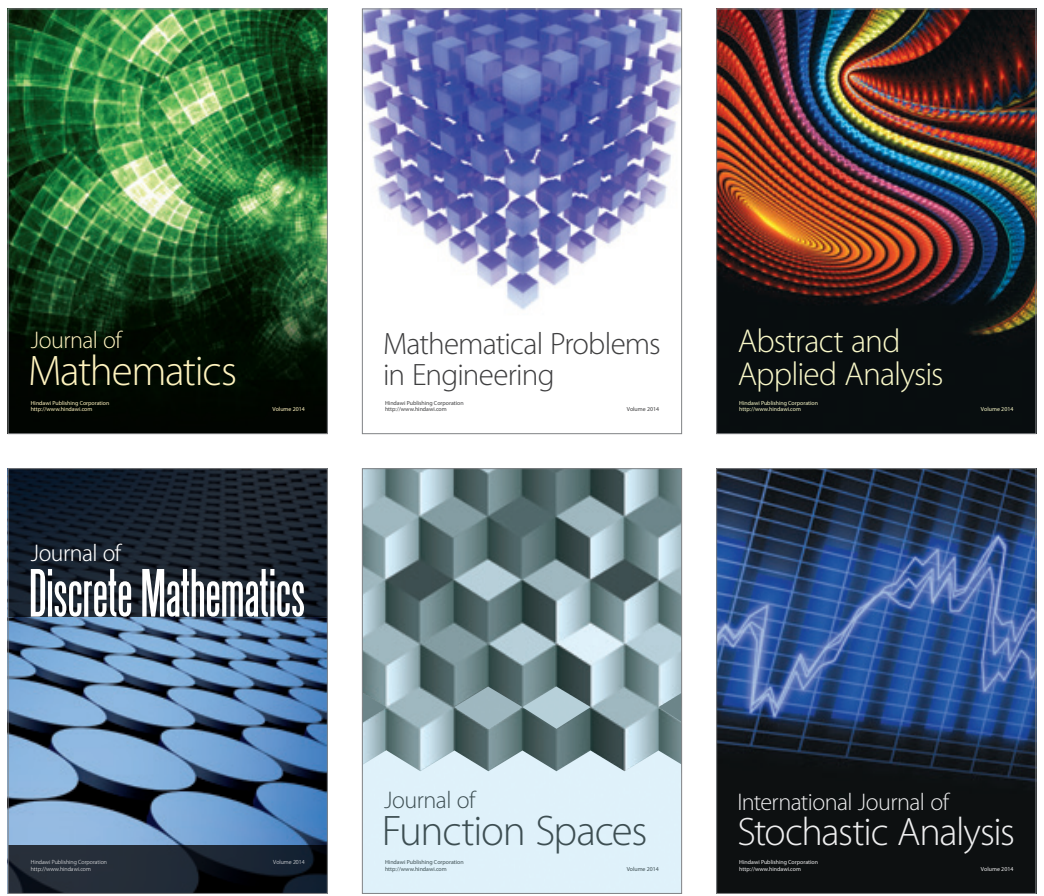

Journal of

Function Spaces

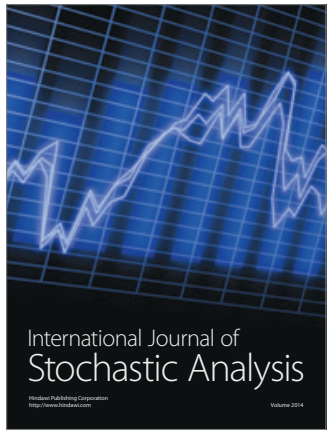

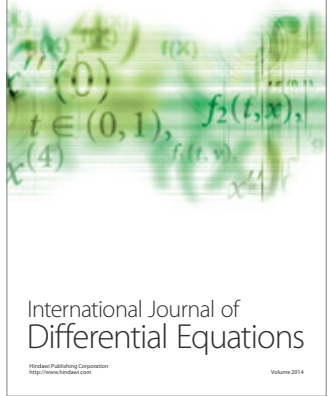
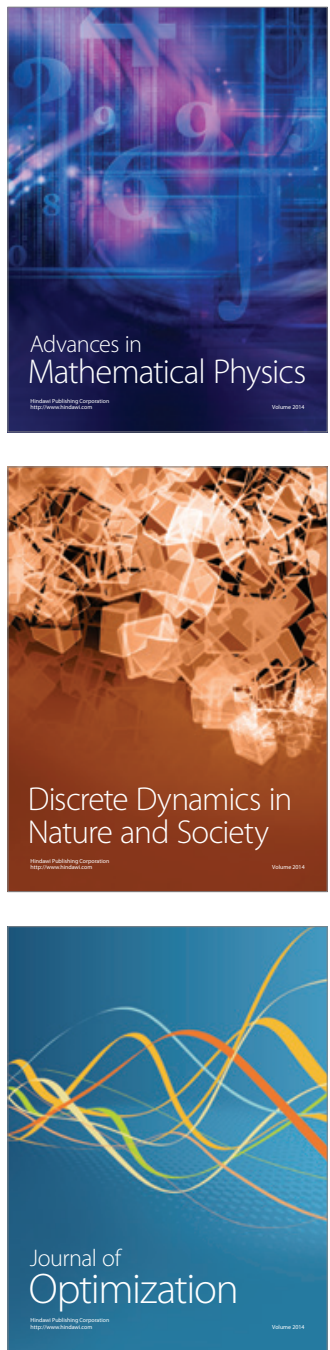